\title{
This Issue in Brief: Gangs, Hot Cars, Hot Spots, and Diversity Training
}

\author{
Lawrence W. Sherman ${ }^{1}$
}

Published online: 14 November 2017

(C) Springer International Publishing AG, part of Springer Nature 2017

Here are the headline summaries of the five research articles in this issue:

- Gang crime in Liverpool dropped by $70 \%$ for 36 months after gang injunctions were issued for individual gang members, compared to the 36 months before injunctions.

- Hot cars detected by Automatic Plate readers in West Midlands were selected for pursuit in a way that focused on less-harmful crimes, with highest harm offences not selected.

- Hot spots patrols in a nighttime entertainment area of Liverpool were reduced in patrol dosage by $35 \%$ with no crime increase, saving $40 \%$ on the costs of hot spots patrols.

- Hot spots patrollers inside two London railway hubs were given feedback on how many of their assignments they completed, with one station increasing patrols delivered but the other station not-with more face-to-face leadership contact where patrols went up.

- Diversity training prevented recruit school decay in attitudes favorable to workplace diversity, in a randomized trial that revealed standard recruit training to leave police less tolerant of gender and race diversity than they had been upon appointment.

All of these articles started out as master's degree theses by full-time police agency employees studying part-time at the University of Cambridge; 4 of the 5 were supported by the (UK) College of Policing and the first author's police agency. All secondary

Lawrence W. Sherman

Lawrence.Sherman@crim.cam.ac.uk

1 Institute of Criminology, Cambridge University, Cambridge, UK 
authors were academic or pracademic supervisors of the master's thesis at various levels. While this journal welcomes submissions from anyone at any university, police agency, or other institution, we are very happy to showcase recent Cambridge work in these short summaries. We are also happy to publish a book review in this issue by a Cambridge MSt graduate of a book by a former Cambridge academic supervisor Cynthia Lum, co-authored with her colleague Christopher Koper, discoverer of the "Koper Curve:"

- Evidence-based policing: translating research into practice (Oxford 2017) is a clear, general introduction to EBP, with many concrete examples of using it in practice.

\section{Gang Crime in Liverpool}

When 36 members of four separate Liverpool gangs were named by police in four separate court-ordered 24-month injunctions, issued at different times, the frequency and harm of crimes the members committed dropped by $70 \%$ over 36 months, compared to 36 months before the injunctions. Fewer criminal events were attributed to $92 \%$ of the individuals in the second 3-year period than in the first, while only $8 \%$ increased their detected activity. Taking the four gangs as the unit of analysis, their offenses dropped by $74 \%$ in the 3 years after the injunctions, with the Crime Harm Index weight of those crimes down $70 \%$. Victimization of the gang members in their 3-year post-injunction period dropped by $60 \%$ compared to the pre-injunction period. While the powers of police to seek these injunctions may not be available in other countries, it is a specific and limited power, reviewed by the courts, that may be effective in combating gang violence in many other nations, as well as UK cities.

\section{Hot Cars on the Motorways}

When Automatic Number Plate Recognition (ANPR) readers in the Birmingham, England area of West Midlands read 70.3 million Vehicle Registration Marks in April 2015, they produced 12,581 Live Alerts of cars wanted by police (including many repeats), for 1488 unique vehicles identified and tracked for this study. A random sample of 210 of the 1488 unique alerts shows that the $49(23 \%)$ selected by dispatchers for police pursuit in marked cars were, on average, wanted in relation to less-harmful crimes than the alerts to which no pursuit car was dispatched. Vehicles that dispatchers did not select for pursuit were wanted in relation to crimes for which the prescribed punishment by sentencing guidelines were $139 \%$ higher (141 days of imprisonment) than average for those dispatched (59 days). This kind of tracking of targeting decisions, in real-time, provides a very concrete example of EBP as embracing a far wider scope of operational policing than just the question of what policies or programs to deploy. 


\section{"Sweet Spots" for Hot Spots Patrols in a Nighttime Entertainment Area?}

A "sweet spot" is a precise point that delivers the best effect, such as the point of a bat that can hit a ball farther than any other point on the bat —or the point of a scale of how many minutes each night police patrol a hot spot. Hot spots policing has focused more on increasing patrol presence than on reducing it, but in many contexts, policing may use higher dosage than necessary to get the same result. With forensic precision using GPS locators in body-worn radios, a small team of Liverpool officers were given sole responsibility for policing five hot spots that had been part of a larger target list for a group of 40 officers. The amount of time any patrol officer spent in those five hot spots, and five other matched hot spots that received the standard "flooding" patrols, delivered a $35 \%$ reduction in patrol dosage with no crime increase, saving $40 \%$ on the costs of hot spots patrols. Rolling out this much reduction in nighttime weekend patrols could save millions a year in police salaries, or reallocate more police time to preventing gang murders.

\section{Feedback and Patrol Presence in Hot Spots}

GPS devices cannot, for technical reasons, be used in every location, but hot spots patrols can be tracked anywhere - by one means or another. Police in two GPS-blind London railway hubs were tracked by their own daily reports of arrival and departure time at each hot spot. These two new quasi-experiments show what can happen when a central analysis team puts the daily reports into a spreadsheet, so that patrol officers can be given feedback on how many of their assignments they completed each week. In theory, feedback should increase completion of assignments. In the experiment, however, only one railway station saw patrol completions increase when feedback was provided. In the other station, the feedback was reportedly conveyed, but there was no change in patrols completed. The first author reports that the difference was associated with one local commander providing more face-to-face contact while feeding back the patrol completion rates to the uniformed patrollers. For the commander using more face time, the proportion of assigned patrols delivered went up. That is not what happened for the other commander, who was brand new to the job and reportedly did not have much face-to-face discussion about feedback on the patrols with the patrollers.

\section{Diversity training prevented recruit school "decay"}

Do police join as idealists but lose their pro-social attitudes in recruit training? Many qualitative studies suggest that they may. But this randomized controlled trial, in Brisbane (Australia), provides the strongest evidence yet for such a problem - and a potential solution. A survey designed to measure attitudes towards workplace diversity and related issues was administered three times to 260 police recruits, who were randomly assigned to receive a values education program (or not) over the 25 -week initial police recruit course. The surveys were conducted (1) in the second week of the 25 -week recruit school course, (2) at the conclusion of the values education program, and (3) 6 weeks after the values program concluded. While the values education 
program did not improve experimental group recruit attitudes towards diversity in the workplace over time, it protected that group from a clear decline in support for diversity associated with the control group - who received only the standard recruit training experience. Because the design was an RCT, the study clearly revealed that the benefit of the program was to serve as a successful buffer against what happened without it: the problematic reduction in support for diversity that prevailed among a random sample of all recruits in three separate entry cohorts.

\section{Book Review: Evidence-Based Policing: Translating Research into Practice}

This excellent book is the first published general introductory book on EBP, with many concrete examples of using it in practice. The book's reviewer, who is an operational police inspector in West Midlands Police, praises the clarity of the book as well as its practical examples. While the book is mostly devoted to the results of testing police practice (with little content about targeting or tracking police practices), the book is a very useful asset for any "first contact" experience that a thoughtful police officer may have with the ideas of evidence-based policing. 